PONTIFÍCIA UNIVERSIDADE CATÓLICA DO RIO DE JANEIRO

\title{
Contemporaneidade e o preparo dos universitários para o mercado de trabalho
}

\section{Letícia Maria da Silva}

Trabalho de Conclusão de Curso

CENTRO de CIÊNCIAS SOCIAIS - CCS

DEPARTAMENTO DE ADMINISTRAÇÃo

Graduação em Administração de Empresas 
Letícia Maria da Silva

Contemporaneidade e o preparo dos universitários para o mercado de trabalho

Trabalho de Conclusão de Curso

Trabalho de Conclusão de Curso, apresentado ao programa de graduação em Administração da PUC-Rio como requisito parcial para a obtenção do título de graduação em Administração.

Orientador(a): Maria Isabel Guimarães

Rio de Janeiro

junho de 2019 


\section{RESUMO}

SILVA, Letícia Maria. Contemporaneidade e o preparo dos universitários para o mercado de trabalho. Rio de Janeiro, 2019. 41 p. Trabalho de Conclusão de Curso - Departamento de Administração. Pontifícia Universidade Católica do Rio de Janeiro.

Estamos passando pela $4^{\mathrm{a}}$ Revolução Industrial, que tem trazido mudanças com uma velocidade exponencial, profunda e de impacto sistêmico. Tal revolução com o surgimento e engajamento de novas tecnologias torna o ambiente volátil, incerto, complexo e ambíguo (mundo VUCA), gerando grandes mudanças na indústria, aumentando a competitividade no mundo dos negócios e trazendo reflexos na força de trabalho. Visto isto, este estudo busca, através de uma pesquisa exploratória qualitativa, entender quais competências ganham maior ênfase segundo a percepção dos gestores, estudantes e professores, para ingressar no mercado de trabalho diante desse cenário. Foram entrevistados quatro estudantes do curso de administração da PUC-Rio, Estácio de Sá e Unicarioca, três professores de administração da PUC-Rio e quatro gestores de $\mathrm{RH}$ que trabalham ou já trabalharam em empresas de grande porte. Através da identificação e comparação das percepções acerca do tema de cada entrevistado, percebeu-se que as competências mais valorizadas são a mentalidade voltada para aprendizagem, inteligência emocional, e habilidades interpessoais, e que, na opinião dos estudantes e gestores, os universitários não estão sendo bem preparados para enfrentar este cenário de mudanças intensas da contemporaneidade.

Palavras-chaves: 4ª $^{\text {a }}$ Revolução Industrial; Competências; Percepção; Metodologias ativas de aprendizagem 


\begin{abstract}
SILVA, Letícia Maria. Contemporary and the preparation of college students for the job market.Rio de Janeiro, 2019. 41p. Undergraduate Thesis - Departamento de Administração. Pontifical Catholic University from Rio de Janeiro.

The 4th Industrial Revolution is being experienced, which brings changes with exponential, deep speed and systemic impact. Such a revolution, the development and engagement of new technologies becomes a volatile, uncertain, complex and ambiguous environment (VUCA), generating major changes in the industry, increasing competitiveness in the business world and bringing reflexes in the work forces. Thus, this study seeks, through a qualitative exploratory research, understand which competences gain greater emphasis according to the perception of managers, students and teachers, to enter the work market in this scenario. Four students from the Business courses from PUC-Rio, Estácio de Sá e Unicarioca were interviewed, such as three professor from PUC-Rio and four HR managers who worked in large companies. Through the identification and comparison of the perceptions about the subject of each interviewee, it was noticed that the most valued competences are the learning mentality, emotional intelligence and interpersonal skills, and that, in students and managers opinion, university students aren't being well prepared to face this scenario of intense changes and contemporaneity.
\end{abstract}

Key words: 4th Industrial Revolution; Competences; Perception; Active Learning Methodology 


\section{SUMÁRIO}

$1.0 \quad$ INTRODUÇÃO

1.1 Tema e Problema de Estudo 6

$\begin{array}{ll}1.2 & \text { Objetivo do Estudo }\end{array}$

$\begin{array}{lll}1.3 & \text { Objetivos Intermediários do Estudo } & 7\end{array}$

1.4 Delimitação e Foco do Estudo 8

1.5 Justificativa e Relevância do Estudo 8

2.0 REVISÃO DE LITERATURA 9

$2.14^{\text {a }}$ Revolução Industrial 9

2.2 Competência 13

$\begin{array}{ll}2.3 \text { Metodologias Ativas de Aprendizagem } & 18\end{array}$

3.0 METODOLOGIA 21

3.1 Escolha dos sujeitos 21

3.2 Limitações 22

4.0 APRESENTAÇÃO E ANÁLISE DOS RESULTADOS 24

4.1 Apresentação dos Resultados 24

4.2 Análise dos Resultados 30

5.0 CONCLUSÃO 35

6.0 REFERÊNCIAS BIBLIOGRÁGICAS 37

ANEXO A - ROTEIRO DE ENTREVISTA PARA PROFESSORES 41

ANEXO B - ROTEIRO DE ENTREVISTA PARA ALUNOS 42

ANEXO C - ROTEIRO DE ENTREVISTA PARA GESTORES 43 


\subsection{INTRODUÇÃO}

\subsection{Tema e Problema de Estudo}

Vivencia-se um momento em que as mudanças estão sendo disruptivas e ocorrendo de maneira muito acelerada devido à $4^{\text {a }}$ Revolução Industrial, que se iniciou na virada do século. Visto isto, o termo "VUCA" - volátil, incerto, complexo e ambíguo- utilizado pelo colégio militar da Pensilvânia em 1987 para descrever a situação geopolítica confusa no período pós-guerra fria, está sendo usado para caracterizar o contexto do mundo atual do ponto de vista empresarial (TH1N1, 2018).

A questão é que à medida em que a tecnologia vai tornando um segmento do mercado ultrapassado, milhares de postos de trabalho são remodelados ou desaparecem e outros cargos vão surgindo de maneira tão rápida que não dá tempo para as pessoas se adaptarem e ocuparem os novos postos.

Além disso, as mudanças nos postos de trabalho podem trazer uma nova ênfase nas competências essenciais à empregabilidade neste cenário de transformação digital e de constantes mudanças. O Fórum Econômico Mundial divulgou o The Future of Jobs Reports (2018), no qual apontou as competências que serão tendência para o mercado em 2022, com destaque para competências comportamentais e interpessoais.

A educação exerce uma forte influência sobre a capacidade dos estudantes obterem sucesso profissional em um contexto complexo como este, e se ela não acompanhar o ritmo das mudanças, a desigualdade social irá aumentar drasticamente segundo Antônio Brasiliano (TNH1, 2018).

Neste contexto, o presente estudo busca responder à seguinte questão: Diante do cenário de mudanças intensas da contemporaneidade, os cursos de Administração, oferecidos pelas universidades PUC- Rio, Unicarioca e Estácio de Sá do Rio de Janeiro, na percepção de estudantes, professores e profissionais de mercado, têm formado profissionais com as competências comportamentais e interpessoais adequadas para o mercado de trabalho? 


\subsection{Objetivo do Estudo}

O objetivo final deste estudo é explorar as percepções das empresas, dos professores e estudantes universitários de administração do Rio de Janeiro acerca das competências comportamentais e interpessoais necessárias para atuar no mercado de trabalho futuro, e entender se, de fato, a formação acadêmica oferecida pelas universidades e faculdades do Rio de Janeiro contempla isto.

\subsection{Objetivos Intermediários do Estudo}

Visando ao objetivo principal, foram traçados objetivos intermediários que serão assinalados a seguir:

- identificar as percepções dos alunos de administração da PUC-Rio, Unicarioca e Estácio de Sá do Rio de Janeiro sobre quais competências o mercado de trabalho busca no administrador para suprir suas demandas atuais e futuras;

- identificar as percepções dos gestores de RH que atuam nos setores de óleo e gás, imobiliário, telecomunicão e de laboratório médico sobre quais competências o mercado de trabalho busca no administrador para suprir suas demandas atuais e futuras; $e$

- $\quad$ identificar as percepções dos professores de administração da PUC-Rio sobre quais competências o mercado de trabalho busca no administrador para suprir suas demandas atuais e futuras.

Comparar as percepções encontradas com os dados obtidos na pesquisa a ser desenvolvida ao longo do projeto, tangibilizando as percepções de alunos, gestores e professores; verificando, então, se o objetivo inicialmente proposto é real e, de fato, existe uma diferença entre as percepções de alunos, gestores e professores em relação ao que esperam as organizações e o mercado de trabalho. 


\subsection{Delimitação e Foco do Estudo}

Este estudo foi delimitado a estudantes de administração do Rio de Janeiro das universidades Estácio, PUC e Unicarioca, a gestores que trabalham ou trabalharam em empresas de grande porte, dos setores de óleo e gás, laboratório médico, imobiliário e telecomunicação e a professores universitários que lecionam na PUC Rio. Em relação às competências avaliadas, enfatizaram-se as comportamentais e interpessoais.

\subsection{Justificativa e Relevância do Estudo}

O mundo mudou e a escola não. Isso trouxe uma consequência importante - um desajuste entre a forma de pensar das pessoas formadas em um modelo tradicional de educação e a necessidade de aprender que as empresas têm hoje. Por um lado, a escola não desenvolve o aprender a aprender e prioriza o paradigma cartesiano, por outro, as empresas precisam inovar e resolver problemas complexos o tempo todo (GUIMARÃES, 2012).

Este trabalho é relevante, primeiramente, para instituições de ensino, que necessitam compreender a percepção do mercado em relação às demandas para adequar o currículo a elas, a fim de suprir pelo menos parcialmente as necessidades do mercado.

Apresenta relevância também para as empresas, pois, ao contribuírem com este estudo, permitirão uma melhor formação de profissionais qualificados que atendam às novas exigências do mercado em um futuro extremamente mutável.

Por fim, é importante para os jovens que cursam ensino superior em Administração, que podem utilizar os resultados para conhecer as percepções dos empregadores referentes às exigências do mercado de trabalho futuro e buscar desenvolver as competências que realmente são indispensáveis para a sua inserção no mercado de trabalho. 


\subsection{REVISÃO DE LITERATURA}

Nesta seção, são apresentados e discutidos alguns conceitos acerca do tema de estudo em investigação e que servirão de base para a análise realizada.

Esta seção está dividida em três partes, que abordam: a 4⿳亠丷a Revolução industrial, competência e metodologias ativas de aprendizagem.

O conceito da 4a Revolução Industrial contribui para o entendimento do contexto atual e dos impactos na força de trabalho. O conceito de competência contribui para a compreensão do objeto deste estudo. Já o referencial acerca das metodologias ativas de aprendizagem contribui para o entendimento da percepção dos professores acerca de o que pode ser feito, em sala de aula, para que as competências comportamentais e interpessoais sejam desenvolvidas, de que forma, e se isso está acontecendo.

\section{$2.1 \quad 4^{\text {a }}$ Revolução Industrial}

A primeira Revolução Industrial aconteceu aproximadamente entre 1760 e 1840, com o início na Grã-Bretanha, quando os métodos de produção artesanais na indústria têxtil foram mecanizados, através do descobrimento do motor à vapor. A mecanização logo chegou em outros setores também e fez surgir novas indústrias, criando novas formas de geração, distribuição e troca de valor. Antes desta revolução, a renda per capta nos países desenvolvidos era de extrema pobreza, e o crescimento médio da economia era de 0,2\% ao ano. Em 1850, o crescimento médio anual econômico aumentou para $2 \%$ a 3\%, impactando intensa e positivamente a renda per capta (SCHWAB, 2018).

O advento da energia elétrica, da produção em massa e do motor de combustão interno marcou a segunda Revolução Industrial, que começou em 1870. Ela trouxe inovações nas infraestruturas físicas, através da iluminação elétrica e programas de saneamento básico, nos meios de comunicação, com o surgimento do telefone, rádio e televisão. Trouxe mudanças disruptivas também 
nos meios de transporte, por intermédio da criação dos aviões (viagens internacionais velozes) e dos carros, cuja produção em massa permitiu o consumo pela população, e na agricultura, através da revolução verde, que aumentou a produção de alimentos e por consequência, o crescimento populacional (SCHWAB, 2018).

A terceira Revolução se deu a partir de 1950 com a revolução digital, quando o uso dos computadores, dos semicondutores, robotização e automação em linhas de produção, com informação armazenada e processada de forma digital se tornaram comum e as comunicações foram caracterizadas pelos computadores móveis (1970 e 1980) e a internet (1990), remodelando praticamente todas as indústrias e mudando de forma drástica a vida profissional e social de grande parte da população (SCHWAB, 2018).

Desde a virada do século, a integração dessas tecnologias, que estão se tornando cada vez mais sofisticadas, tem gerado mudanças disruptivas na sociedade e na economia global, indicando o início da $4^{a}$ Revolução Industrial. Segundo o relatório o futuro dos trabalhos ${ }^{1}$ (2018) e Schawb (2016) as principais características dessa revolução são os avanços na inteligência artificial e aprendizagem automática (ou de máquina), internet mais onipresente, veloz e móvel, sensores menores, mais potentes e mais baratos, adoção generalizada de análise de big data; e a tecnologia em nuvem.

O evento que foi o marco para o início da 4⿳亠丷a Revolução industrial, foi a feira de Hannover em 2011, onde o Governo Federal Alemão mostrou uma série de ações estratégicas voltadas para a tecnologia que possibilitam a transformação da cadeia de valor global, através das chamadas fábricas inteligentes (JUNIOR e SALTORATO, 2018). Essas fábricas inteligentes são compostas pela união das seguintes tecnologias:

- Sistema físico cibernético (CPS) - sistemas que integram computação, redes de comunicação, computadores embutidos e processos físicos interagindo entre si e influenciando-se mutuamente (Costa 2017, p.9);

\footnotetext{
${ }^{1}$ Relatório gerado a partir de entrevistas com executivos de alto escalão de nove grandes setores, em 15 mercados emergentes e desenvolvidos, cuja quantidade de colaboradores somadas resultam em 13 milhões de pessoas.
} 
- Internet das coisas (lot) - objetos com sensores que criam uma enorme rede conectada à internet, pela qual coletam e transmitem dados. (Costa 2017, p.9);

- Internet em nuvem (loS) - "fornecimento de serviços de computação através de servidores, armazenamento, bancos de dados, rede, software, análise entre outros, através da Internet" (Brito, 2017, p.4).

A fusão dessas tecnologias aplicadas a um ambiente de produção resultam na Indústria 4.0. A combinação delas permite uma produção muito mais eficiente, em que as máquinas se comunicam e se integram com outras máquinas, pessoas e recursos, tornando os processos mais ágeis, econômico, autônomo e com possibilidade de gerenciamento aprofundado (JUNIOR e SALTORATO, 2018; TOTVS, 2018).

Diante disto alguns países já tomaram ações, como os EUA, que anunciaram em 2011 a AMP (Advanced Manufacturing Partership), cujo objetivo é promover investimentos em tecnologias emergentes através da união entre universidades, governo federal e indústrias, e em 2014 a AMP 2.0 (Acelerating US Advanced Manufacturing) com ações para acelerar e elevar a capacidade de manufatura avançada dos EUA (JUNIOR e SALTORATO, 2018).

O Brasil anunciou uma Agenda para a Indústria 4.0, apontando 10 medidas pragmáticas que abrangem: difusão do conhecimento acerca do tema para as empresas; seleção de empresas através da autoavaliação; prototipação de fábricas inteligentes, com direito a Hub para a busca de fornecedores de tecnologia; Brasil mais produtivo (apoiar a aplicação de manufatura enxuta em empresas de médio porte); testes das fábricas inteligentes; conexão com aproximadamente 100 startups para apoiar 50 indústrias no processo de modernização; enquadramento aos requisitos legais e de talentos; reformas legais e infralegais que promovam a indústria 4.0; financiabilidade; construção de conexões globais (Agenda do Governo).

É preciso saber mais sobre porque a $4^{\mathrm{a}}$ Revolução Industrial é diferente das outras e os impactos que ela pode gerar. Schwab (2016) aponta 3 aspectos que respondem isto. O primeiro é a velocidade, já que novas tecnologias fazem surgir outras mais rebuscadas e qualificadas, e a digitalização e a tecnologia da 
informação tem alto poder de disseminação, gerando um crescimento exponencial. O segundo é a amplitude e profundidade, que está trazendo mudanças importantes no indivíduo, em relação ao tipo e à forma como pessoas realizam suas atividades, na sociedade, nos negócios e na economia, culminando no terceiro aspecto, o impacto sistêmico (transformações em sistemas inteiros da sociedade).

A 4⿳a Revolução industrial trará mudanças no âmbito econômico, interferindo no PIB, consumo, emprego, inflação, comércio e investimentos; no âmbito político, já que há a necessidade de novas regulamentações que fomentem as tecnologias digitais; na demanda dos consumidores, já que os novos modelos de negócio permitirão atender os clientes de forma mais personalizada com baixo custo (SCHWAB, 2016); na indústria, já que as fábricas inteligentes trarão, entre outras coisas, mais flexibilidade na linha de produção; e na força de trabalho, assunto ao qual o presente estudo dará maior ênfase. (JUNIOR e SALTORATO, 2018).

Dentro das diversas tendências que o Relatório o Futuro dos Trabalhos de 2016 expõe, destacam-se a automatização dos trabalhos operacionais, com uma migração da força de trabalho para atividades e funções que demandem imaginação, criatividade e estratégia; Remodelagem quase completa dos cargos e funções daqui a 10 anos - De acordo com Foursale (2019), 65\% dos estudantes de Ensino Fundamental hoje terão de trabalhar em funções totalmente novas no futuro. Além disso, este relatório aponta que 7,1 milhões de empregos serão perdidos contra 2 milhões que serão criados até 2020.

Junior e Saltorato (2018), dizem que um dos prováveis impactos da indústria 4.0 é a expansão de trabalhadores independentes contratados para a realização de serviços pré-determinados através de plataformas digitais, por um curto período de tempo, e em um contexto de insegurança e ausência de benefícios.

O estudo feito por Junior e Saltorato intitulado por impactos da indústria 4.0 na organização do trabalho: Uma revisão sistemática da literatura, faz uma relação de autores com os principais impactos que a 4⿳亠丷厂 Revolução Industrial causará na força de trabalho, como pode ser vista a seguir: 
QUADRO 1 - Relação de Impacto/Fonte

\begin{tabular}{|c|c|}
\hline IMPACTO & FONTE \\
\hline $\begin{array}{c}\text { Aumento do desemprego tecnológico, em } \\
\text { contrapartida a criação e/ou aumento de } \\
\text { postos de trabalho mais complexos e } \\
\text { qualificados }\end{array}$ & $\begin{array}{c}\text { BCG (2015b) } \\
\text { Becker e Stern (2016) } \\
\text { Edwards e Ramirez (2016) } \\
\text { Freddi (2017) } \\
\text { Peters (2016) } \\
\text { Salento (2017) } \\
\text { Weber (2016) } \\
\text { WEF (2016) }\end{array}$ \\
\hline $\begin{array}{l}\text { Necessidade de desenvolvimento de novas } \\
\text { competências e habilidades }\end{array}$ & $\begin{array}{c}\text { BCG (2015b) } \\
\text { Benesova e Tupa (2017) } \\
\text { Edwards e Ramirez (2016) } \\
\text { Gehrke et al (2015) } \\
\text { Heclkau et al (2016) } \\
\text { Jasiulewicz-kaczmarek et al (2017) } \\
\text { Schuh et al (2015) } \\
\text { Weber (2016) } \\
\text { WEF (2016; 2017) }\end{array}$ \\
\hline Maior interação entre o homem e a máquina & $\begin{array}{c}\text { BCG (2015b) } \\
\text { Romero et al (2016) }\end{array}$ \\
\hline $\begin{array}{l}\text { Transformaçōes nas relaçōes } \\
\text { socioprofissionais }\end{array}$ & $\begin{array}{c}\text { Caruso (2017) } \\
\text { Edwards e Ramirez (2016) } \\
\text { Gorecky et al (2014) } \\
\text { Hirsch-Kreinsen (2016) } \\
\text { Jasiulewicz-kaczmarek et al (2017) } \\
\text { Shamim (2016) } \\
\text { WEF (2016) }\end{array}$ \\
\hline
\end{tabular}

Fonte: JUNIOR e SALTORATO, 2018 p.757.

Dentro desses impactos, o presente estudo se delimita a avaliar a necessidade de desenvolvimento de novas competências, enfatizando as competências comportamentais e interpessoais de acordo com as percepções de estudantes universitários de administração, gestores do mercado que trabalham ou trabalharam com seleção de pessoas em grandes empresas ou grandes eventos e professores universitários.

\subsection{Competência}

O conceito de competência tem sofrido mudanças na literatura, devido à $4^{a}$ Revolução Industrial, que tem tornado o contexto cada vez mais complexo, volátil, incerto e ambíguo, trazendo demandas e impactos quase que imprevisíveis para as empresas. Diante disto, as organizações necessitam reajustar as suas estratégias e captar recursos humanos com competências que possibilitem uma atuação de sucesso neste novo cenário. 
O conceito de competência mais obsoleto está relacionado à ideia de capacidade, que seria o conjunto dos conhecimentos- o saber-, habilidades - 0 saber fazer- e atitudes - o saber fazer acontecer-, desenvolvidos por uma pessoa ao longo do tempo, através da formação acadêmica ou experiência no mercado de trabalho. Estas capacidades devem estar combinadas e mobilizadas para atender à demanda do trabalho (BORBA, 2011).

Fleury e Fleury (2013) dizem que, historicamente, o conceito de competência está ligado a um estoque de recursos (conhecimentos, habilidades e atitudes, associados à inteligência e personalidade da pessoa) que gera um desempenho superior na realização de uma tarefa, e que sua avaliação é feita em relação ao conjunto de tarefas do cargo ou posição ocupada pela pessoa. Entretanto, isto não é suficiente para atender as demandas das empresas por flexibilidade e inovação no contexto atual, que torna comum a assunção de um papel reativo das empresas e stakeholders diante de situações complexas, em que até existam informações, mas são difíceis de serem processadas e aprendidas. Neste contexto, adaptar-se às mudanças e antecipar tendências é um diferencial competitivo e passa a ser um fator fundamental para a sobrevivência das organizações (GUIMARÃES, 2012).

Uma definição mais recente para este termo é a de Zarifian (2013), que diz:

Competência é a tomada de iniciativa e o assumir de responsabilidade do indivíduo sobre problemas e eventos que ele enfrenta em situações profissionais [...] É uma inteligência prática das situações que se apoia em conhecimentos adquiridos e os transforma à medida que a diversidade das situações aumenta [...] É a faculdade de mobilizar redes de atores em volta das mesmas situações, de compartilhar desafios, de assumir áreas de responsabilidade (ZARIFIAN, 2013).

Fleury e Fleury (2013, p.31) apresentam um quadro citando as competências que denotam valor para o indivíduo e para a organização, que pode ser compreendida através dos tópicos a seguir:

- $\quad$ "Saber agir" - saber o que faz, porque faz e saber decidir; 
- "Saber mobilizar" diferentes tipos de recursos para integrá-los na organização (pessoas, capital, informações e conhecimento, parcerias etc.);

- "Saber comunicar" de maneira eficaz, compreendendo, processando e transmitindo conhecimentos e informações, sempre certificando o entendimento da mensagem pelo receptor;

- "Saber aprender" - saber rever os próprios modelos mentais, propiciar o autodesenvolvimento e o desenvolvimento dos outros. Aprender adquirindo conhecimento e experiências;

- "Saber comprometer-se" e ter engajamento com os objetivos organizacionais;

- "Saber assumir responsabilidades", riscos e impactos que cada decisão tomada irá tomar nos ambientes internos e externos da empresa, e ser reconhecido por isto

- "Ter visão estratégica" é entender de forma profunda o próprio negócio e o ambiente no qual está inserido, identificando as forças, fraquezas, oportunidades, ameaças e vantagens ou desvantagens competitivas.

Junior e Saltorato (2018) classificam competência em três categorias: Competências funcionais, que se compreendem naquelas essenciais para a execução técnica das tarefas; Competências comportamentais, relacionadas às atitudes do indivíduo; Competências sociais, relacionadas à interação e ao trabalho em equipe.

A seguir é possível observar a relação dessas 3 categorias com as competências requeridas pela Indústria 4.0 de acordo com a revisão sistemática da literatura feita por Junior e Saltorato (2018). 
QUADRO 2 - Competências Funcionais, Comportamentais e Sociais

\begin{tabular}{|c|c|}
\hline \multirow{6}{*}{$\begin{array}{l}\text { Competências } \\
\text { funcionais }\end{array}$} & Resolução de problemas complexos \\
\hline & Conhecimento avançados em TI, incluindo codificação e programação \\
\hline & Capacidade de processar, analisar e proteger dados e informações \\
\hline & Operação e controle de equipamentos e sistemas \\
\hline & Conhecimento estatístico e matemático \\
\hline & Alta compreensão dos processos e atividades de manufatura \\
\hline \multirow{6}{*}{$\begin{array}{l}\text { Competências } \\
\text { comportamentais }\end{array}$} & Flexibilidade \\
\hline & Criatividade \\
\hline & Capacidade de julgar e tomar decisões \\
\hline & Autogerenciamento do tempo \\
\hline & Inteligência emocional \\
\hline & Mentalidade orientada para aprendizagem \\
\hline \multirow{6}{*}{$\begin{array}{l}\text { Competências } \\
\text { sociais }\end{array}$} & Habilidade de trabalhar em equipe \\
\hline & Habilidades de comunicação \\
\hline & Liderança \\
\hline & Capacidade de transferir conhecimento \\
\hline & Capacidade de persuasão \\
\hline & Capacidade de comunicar-se em diferentes idiomas \\
\hline
\end{tabular}

Fonte: Impactos da indústria 4.0 na organização do trabalho: Uma revisão sistemática da literatura, 2018, p. 761.

Abaixo, há uma relação TOP 10 de competências que são demandadas hoje no mercado de trabalho mundial, que serão tendência em 2022 e que estarão em declínio no mesmo ano, segundo o relatório O Futuro dos Trabalhos: 
QUADRO 3 - TOP 10 Competências

\begin{tabular}{|c|c|c|}
\hline 2018 & TENDÊNCIAS 2022 & DECLÍNIO 2022 \\
\hline $\begin{array}{l}\text { - } \\
\text { analítico } \\
\text { - } \quad \text { Inovação } \\
\text { - } \quad \text { Resolução de } \\
\text { problemas complexos } \\
\text { - } \quad \text { Aprendizagem ativa } \\
\text { e estratégias de } \\
\text { aprendizagem } \\
\text { - } \quad \text { Criatividade, } \\
\text { originalidade e iniciativa } \\
\text { - } \quad \text { Inteligência } \\
\text { emocional } \\
\text { - } \quad \text { Raciocínio lógico, } \\
\text { resolução de problemas e } \\
\text { ideação } \\
\text { - } \quad \text { Liderança e } \\
\text { influência social } \\
\text { - } \quad \text { gestão de equipe e } \\
\text { coordenação } \\
\text { - Atenção aos detalhes } \\
\text { e confiabilidade }\end{array}$ & $\begin{array}{l}\text { - } \\
\text { originalidadividade } \text { e iniciativa } \\
\text { - } \quad \text { Inovação } \\
\text { problemas complexos } \\
\text { - } \quad \text { Aprendizagem ativa } \\
\text { e estratégias de } \\
\text { aprendizagem } \\
\text { - } \quad \text { Pensamento crítico e } \\
\text { analítico } \\
\text { - } \quad \text { Inteligência } \\
\text { emocional } \\
\text { - } \quad \text { Ideação } \\
\text { - } \quad \text { Liderança e } \\
\text { influência social } \\
\text { - } \quad \text { Design e } \\
\text { programação de tecnologia } \\
\text { - } \quad \text { Análise e avaliação } \\
\text { de sistemas } \\
\text { - } \quad \text { Raciocínio lógico, } \\
\text { resolução de problemas }\end{array}$ & $\begin{array}{l}\text { - } \quad \text { Destreza manual } \\
\text { resistência e precisão } \\
\text { - } \quad \text { Memória, habilidades } \\
\text { verbais, auditivas e } \\
\text { espaciais } \\
\text { - } \quad \text { Gestão de recursos } \\
\text { financeiros, materiais } \\
\text { - } \quad \text { Instalação e } \\
\text { manutenção de tecnologia } \\
\text { - } \quad \text { Leitura, escrita, } \\
\text { matemática e audição ativa } \\
\text { - } \quad \text { Gestão de pessoal } \\
\text { Controle de qualidade e } \\
\text { conscientização de } \\
\text { segurança } \\
\text { - } \quad \text { Coordenação e } \\
\text { gestão do tempo } \\
\text { - } \quad \text { Habilidades visuais, } \\
\text { auditivas e de fala } \\
\text { • Uso, monitoramento } \\
\text { e controle de tecnologia }\end{array}$ \\
\hline
\end{tabular}

Fonte: WEF, 2018, p.12.

A pesquisa realizada buscou identificar se os entrevistados percebem estas competências como importantes ou não para atuar no mercado de trabalho presente e futuro, e como elas são desenvolvidas (e se são) nos cursos de graduação. 


\subsection{Metodologias Ativas de Aprendizagem}

O método tradicional de ensino, em que os alunos estão enfileirados recebendo passivamente o conteúdo passado pelo professor, que é o protagonista da sala de aula, trata os alunos como se fossem uma linha de produção, não levando em consideração as dificuldades e facilidades peculiares de cada aluno no processo de aprendizagem (BERGMAN e SAMS,2017).

\footnotetext{
Apesar de a escola ser uma instituição que tem como objetivo central a aprendizagem, o que se tem percebido - pela avaliação de seus resultados e de estudos e pesquisas de diversos autores - é que, por causa de seu currículo e sua metodologia adequados à sociedade industrial, ela não tem oportunizado a aprendizagem generativa e nem o desenvolvimento das competências para aprender, necessárias à sociedade do conhecimento (GUIMARÃES, 2012).
}

A maioria dos sistemas educacionais atuais está formatada para atender as necessidades do mercado do passado, sec. XVIII e XIX, época em que o sistema de educação em massa surgiu. As academias de ensino valorizam mais disciplinas como matemática, ciências e línguas, já que eram necessárias para a execução das funções industriais, desprezando as outras que envolvam os sentidos, o coração e o corpo (ROBINSON, 2010).

Além disso, autores como Pink (2009) e Alves (2001) consideram a metodologia tradicional de ensino como método que gera mais conformismo que engajamento, que está mais focado em questões rotineiras, respostas certas e padronização, do que em criatividade e diversidade. Todos os alunos recebem o mesmo conteúdo, são ensinados de maneira igual, e ao mesmo tempo, e se algum aluno não se encaixa no padrão estabelecido recebe notas baixas -estímulo negativo-, não levando em conta os seus pontos fortes que possam ser potencializados. Isto é muito complicado, pois o mercado demanda hoje a criatividade e a junção de pessoas com diferentes competências para tornar uma equipe mais completa, abrangente e capacitada a responder ou agir de forma coletiva e inovadora (GUIMARÃES, 2017). 
O estudo de Guimarães (2012, p. 22) sintetiza em um quadro as características das escolas tradicionais que precisam ser transformadas para atender as necessidades do mercado atual.

QUADRO 4 - Escola Tradicional x Nova Escola

\begin{tabular}{|l|l|l|}
\hline Aspectos & Escola Tradicional & Nova Escola \\
\hline Objetivo & Transmissão de informaç̃̃es & Desenvolvimento humano \\
\hline Currículo & Disciplinas e séries & Competências e habilidades \\
\hline Método & Ensino & Projetos de aprendizagem \\
\hline Professor & Transmissor de informações & Orientador e facilitador \\
\hline Aluno & Plateia passiva & Protagonista e ativo \\
\hline Gestão & Hierárquica e autoritária & Democrática e participativa \\
\hline Espaço e tempo & Sala de aula e aula & Diversificados e flexíveis \\
\hline Estrutura & Linear, em séries & Em rede, aberta, sem séries \\
\hline Atitude & Fechada em si mesma & Aberta para a vida e o mundo \\
\hline Tecnologia & Apoio ao ensino & Apoio à aprendizagem \\
\hline
\end{tabular}

Fonte: GUIMARÃES, 2012, p. 22.

Enquanto a escola tradicional tem o objetivo somente de transmitir informações aos alunos, que seria a herança cultural da humanidade, a escola com metodologias ativas de aprendizagem tem como objetivo oferecer ao aluno a oportunidade de desenvolver e potencializar os próprios talentos, fazendo com que o foco da aprendizagem seja nos sonhos e necessidades de cada aluno.

Desse modo, o currículo se adequaria às competências e habilidades que o aluno deseja desenvolver. Ao trazer o currículo muito segmentado em disciplinas e séries, a escola tradicional dificulta o desenvolvimento de uma visão sistêmica, competência esta inerente à vida real e procurada pelas organizações.

Enquanto na escola tradicional o aluno recebe as informações de forma passiva, o método da nova escola usando projetos de aprendizagem faz com que ele se torne o protagonista do processo, abrindo espaço para a aprendizagem exploratória (que significa forma de aprender por si mesmo, segundo o dicionário Priberam) e colaborativa (interagindo com os outros) (BERGMAN e SAMS, 2017; GUIMARÃES, 2012). Esses aspectos são essenciais para aprender a aprender e são negligenciados no método de ensino tradicional (GUIMARÃES, 2012). 
Tal mudança faz com que o professor e o aluno assumam um papel mais desafiador, o primeiro como orientador e facilitador e o segundo como aprendiz ativo. Além disso, tornar a gestão da escola mais democrática e participativa estimula 0 aluno a desenvolver relações horizontais e parcerias. O uso de tecnologia traz flexibilidade em termos de tempo e espaço, permitindo que os alunos tenham mais oportunidades de aprender e, com os meios de comunicação, ampliem a interação com outras escolas e outros alunos. A nova escola tem o aluno como protagonista em cada aspecto, e competências como mentalidade voltada à aprendizagem, trabalho em equipe, muito exigidas pelo mercado, são bastante trabalhadas pelas metodologias ativas. 


\subsection{METODOLOGIA}

Este estudo é exploratório qualitativo, que busca:

Prover critérios e compreensão. Tem as seguintes características: informações definidas ao acaso e o processo de pesquisa flexível e nãoestruturado. A amostra é pequena e não-representativa e a análise dos dados é qualitativa. As constatações são experimentais e o resultado, geralmente, seguido por outras pesquisas exploratórias ou conclusivas (OLIVEIRA, 2011).

Trata-se de um estudo teórico-empírico, no qual foi realizado um estudo bibliográfico e documental, apresentando conceitos extraídos de livros, trabalhos acadêmicos e documentários, e um estudo de campo, baseado em entrevistas, com o objetivo de buscar o significado dos dados coletados (OLIVEIRA, 2011). O roteiro das perguntas foi semiestruturado, com perguntas abertas para que se pudesse captar de forma fidedigna a percepção que o entrevistado tem acerca do tema deste estudo.

\subsection{Escolha dos sujeitos}

A escolha dos entrevistados foi por conveniência, selecionando aqueles que fazem parte da rede de contatos da autora do estudo. Abaixo pode ser conferido um quadro que apresenta o perfil de cada entrevistado, cujos nomes são fictícios. 
QUADRO 5 - Perfis dos entrevistados

\begin{tabular}{|c|c|c|}
\hline GESTORES & ALUNOS & PROFESSORES \\
\hline $\begin{array}{l}\text { LUÍS CARLOS } \\
\text { Business Partner da Labs } \\
\text { Dor - Tem } 5 \text { anos de carreira } \\
\text { na área de Recursos } \\
\text { Humanos }\end{array}$ & $\begin{array}{l}\text { LUCAS } \\
\text { (Unicarioca - Administração } \\
\text { 3o período) } \\
\text { Está no } 2 \text { o emprego como } \\
\text { auxiliar administrativo }\end{array}$ & $\begin{array}{l}\text { SOLANGE } \\
7 \text { anos como professora. } \\
\text { Leciona na PUC-RIO e ESPM } \\
\text { disciplinas nas áreas de } \\
\text { organizações e finanças }\end{array}$ \\
\hline $\begin{array}{l}\text { BEATRIZ } \\
\text { coordenadora de } \\
\text { desenvolvimento } \\
\text { organizacional da Ipiranga - } \\
\text { Tem } 16 \text { anos de carreira }\end{array}$ & $\begin{array}{l}\text { SABRINA } \\
\text { (PUC - Administração- } \\
\text { penúltimo período) } \\
\text { Estagia a } 2 \text { anos em uma } \\
\text { empresa de investimentos } \\
\text { financeiros }\end{array}$ & $\begin{array}{l}\text { PEDRO ANTÔNIO } \\
25 \text { anos como professor. } \\
\text { Leciona na PUC-RIO, na } \\
\text { graduação e MBA, e na FGV, } \\
\text { no mestrado, disciplinas na } \\
\text { área de organizações }\end{array}$ \\
\hline $\begin{array}{l}\text { ALEXANDRE } \\
\text { Diretor de Vendas da Real } \\
\text { Up Imobiliária - Trabalhou } \\
\text { por } 10 \text { anos coordenando } \\
\text { eventos esportivos mundiais }\end{array}$ & $\begin{array}{l}\text { LUÍZA } \\
\text { (PUC - Administração- } \\
\text { penúltimo período) } \\
\text { Não está estagiando no } \\
\text { momento, mas já estagiou }\end{array}$ & $\begin{array}{l}\text { AUGUSTO } \\
20 \text { anos como professor. } \\
\text { Leciona na PUC-RIO e UERJ } \\
\text { disciplinas na área de } \\
\text { marketing, entre outras }\end{array}$ \\
\hline $\begin{array}{l}\text { HELOÍSA } \\
\text { Psicóloga, grafóloga, } \\
\text { coaching e analista de } \\
\text { comportamento. Atua na } \\
\text { equipe de RH de uma } \\
\text { empresa Brasileira de } \\
\text { grande porte no setor de } \\
\text { telecomunicação }\end{array}$ & $\begin{array}{l}\text { VITÓRIA } \\
\text { (Estácio- Administração - 1o } \\
\text { período) fez por quase } 2 \text { anos } \\
\text { processos gerenciais e } \\
\text { depois trocou. Estagiou como } \\
\text { auxiliar administrativo em } \\
\text { mais de } 2 \text { empresas. }\end{array}$ & \\
\hline
\end{tabular}

Fonte: A autora

\subsection{Limitações}


Uma das limitações deste estudo são os vieses que podem ter influenciado a elaboração do roteiro de entrevista e a resposta dos entrevistados. O fato de não ter entrevistado ex-alunos universitários, que já estão inseridos no mercado de trabalho, pode, também, ser considerado uma limitação deste estudo. 


\subsection{APRESENTAÇÃO E ANÁLISE DOS RESULTADOS}

\subsection{Apresentação dos Resultados}

Antes de apresentar os resultados, vale lembrar que as competências focadas nesse estudo são as comportamentais e interpessoais, não levando em consideração as técnicas. Como balizador para a realização das entrevistas e construção dos quadros, utilizou-se a relação top 10 de competências do relatório o futuro dos trabalhos (2018), elaborado pelo Fórum Econômico Mundial. Em todos os quadros que serão apresentados, o parâmetro para presente é o ano 2019, e futuro, 2022 (Também utilizado no relatório O futuro dos trabalhos de 2018).

A seguir serão apresentadas em quadros as opiniões consolidadas de cada grupo entrevistado. As entrevistas foram realizadas individualmente e foram gravadas. Os trechos principais, que revelam a opinião sobre os questionamentos, que podem ser conferidos nos anexos, foram transcritos. Os trechos que não estão diretamente relacionados com o foco principal do estudo, como o currículo dos entrevistados, não foram transcritos, mas sim resumidos e colocados em tópicos. A partir do resumo e transcrição de cada entrevista, foram elaborados os quadros de cada grupo.

Abaixo estão as opiniões consolidadas dos quatro gestores entrevistados em relação às competências necessárias para o graduando de administração ingressar no mercado de trabalho atual e estar inserido no mercado de trabalho futuro.

QUADRO 6 - As Competências Mais Importantes - Profissionais

\begin{tabular}{|c|c|c|c|}
\hline \multicolumn{4}{|c|}{$\begin{array}{l}\text { As competências que os } 4 \text { profissionais entrevistados consideram mais } \\
\text { importantes }\end{array}$} \\
\hline & PRESENTE & FUTURO & LACUNA ENSINO \\
\hline LUís & Capacidade & Idem ao lado; & Saber fazer \\
\hline
\end{tabular}




\begin{tabular}{|c|c|c|c|}
\hline $\begin{array}{l}\text { CARLOS } \\
\text { (Business } \\
\text { Partner da } \\
\text { Labs Dor) }\end{array}$ & $\begin{array}{l}\text { analítica - trazer soluções } \\
\text { para os problemas da } \\
\text { empresa; } \\
\text { - } \quad \text { Resiliência; } \\
\text { - } \quad \text { Foco em } \\
\text { resultado - } \\
\text { trabalhabilidade; } \\
\text { - } \quad \text { Ser autodidata; } \\
\text { - } \quad \text { Visão sistêmica; }\end{array}$ & $\begin{array}{l}\text { - } \quad \text { Aprender a } \\
\text { aprender; } \\
\text { - } \quad \text { Polivalência } \\
\text { (interdisciplinaridade); } \\
\text { - } \quad \text { Conhecimentos } \\
\text { de ti; }\end{array}$ & \\
\hline $\begin{array}{l}\text { BEATRIZ } \\
\text { (coordenado } \\
\text { ra de } \\
\text { desenvolvim } \\
\text { ento } \\
\text { organizacion } \\
\text { al da } \\
\text { Ipiranga) }\end{array}$ & $\begin{array}{l}\text { - Atitude - ser } \\
\text { empreendedor, ter } \\
\text { espírito de dono do } \\
\text { negócio; } \\
\text { - Estar em } \\
\text { constante aprendizado; } \\
\text { aprender a aprender; } \\
\text { - Saber trabalhar } \\
\text { em ambiente flexível; }\end{array}$ & $\begin{array}{l}\text { - } \quad \text { Inovação; } \\
\text { - } \quad \text { Aprendizagem } \\
\text { ativa - autodidata, } \\
\text { reaprender; } \\
\text { - } \quad \text { Resolução de } \\
\text { problemas complexos; } \\
\text { - } \quad \text { Design e } \\
\text { programação de } \\
\text { tecnologia; }\end{array}$ & $\begin{array}{l}\text { - Saber pôr a } \\
\text { mão massa. Não ter } \\
\text { apenas teoria; }\end{array}$ \\
\hline $\begin{array}{l}\text { ALEXANDR } \\
\text { E } \\
\text { (Diretor de } \\
\text { Vendas da } \\
\text { Real Up } \\
\text { Imobiliária- } \\
\text { Trabalhou } \\
\text { por } 10 \text { anos } \\
\text { coordenand } \\
\text { o eventos } \\
\text { esportivos } \\
\text { mundiais) }\end{array}$ & $\begin{array}{l}\text { - Saber lidar com } \\
\text { as diferenças das } \\
\text { pessoas e identificar no } \\
\text { colaborador o que ele tem } \\
\text { de melhor e potencializar } \\
\text { aquilo; } \\
\text { - } \quad \text { Falar inglês; }\end{array}$ & $\begin{array}{l}\text { - } \quad \text { Resolução de } \\
\text { conflitos no grupo; } \\
\text { - } \quad \text { Criatividade, } \\
\text { originalidade; } \\
\text { - Inovação, já que } \\
\text { todo mundo tem acesso } \\
\text { à tudo; } \\
\text { - } \quad \text { Gestão de } \\
\text { pessoas; } \\
\text { - } \quad \text { Experiência, } \\
\text { embora o mercado não } \\
\text { dê oportunidade para o } \\
\text { profissional ter } \\
\text { experiência; }\end{array}$ & $\begin{array}{l}\text { - Experiência e } \\
\text { especialização. Isso } \\
\text { não é a função da } \\
\text { faculdade, é o aluno } \\
\text { que deve buscar por } \\
\text { fora; }\end{array}$ \\
\hline $\begin{array}{l}\text { HELOÍSA } \\
\text { (Psicóloga, }\end{array}$ & $\begin{array}{l}\text { - Competências } \\
\text { Comportamentais, como } \\
\text { inteligência emocional, }\end{array}$ & - & $\begin{array}{l}\text { - Experiência e } \\
\text { competências } \\
\text { comportamentais, mas }\end{array}$ \\
\hline
\end{tabular}




\begin{tabular}{|l|l|l|l|}
\hline grafóloga, & resiliência; & & $\begin{array}{l}\text { essa não é a função } \\
\text { coaching e }\end{array}$ \\
$\begin{array}{l}\text { analista de } \quad \text { Conhecer a área } \\
\text { que a empresa atua, mas }\end{array}$ & $\begin{array}{l}\text { ser especialista em lidar } \\
\text { comportame } \\
\text { nto) }\end{array}$ & & \\
\hline
\end{tabular}

Fonte: A autora.

É importante destacar que aprendizagem ativa, resolução de problemas, resiliência e saber lidar com as pessoas se repetem nas opiniões dos gestores como competências essenciais para agora e para o futuro. Tais competências são citadas no estudo de Junior e Saltorato (2018) e estão inclusas no TOP 10 de competências do relatório O Futuro dos Trabalhos de 2018.

Quando foi perguntado aos gestores se eles acham que os universitários saem bem preparados da universidade para enfrentar o mercado de trabalho, a resposta unânime foi "não". As justificativas estão apresentadas na coluna lacunas do ensino, na qual destaca-se, por unanimidade, a falta de experiência, a falta de saber aplicar o conhecimento de forma prática, de saber fazer e gerar resultados com aquele conhecimento. Percebe-se que esta lacuna se torna um ciclo ao qual ninguém se declara culpado.

Abaixo, está o resumo das percepções de cada aluno de administração entrevistado sobre as competências exigidas pelo mercado de trabalho diante da 4⿳亠丷厂 revolução:

QUADRO 7 - As Competências Mais Importantes - Alunos

As competências que os 4 estudantes entrevistados mais consideram importantes

\begin{tabular}{|c|c|c|c|}
\hline & PRESENTE & FUTURO & Lacuna ensino \\
\hline $\begin{array}{l}\text { LUCAS } \\
\text { (Unicarioca - } \\
\text { Administração } \\
\text { 3o período) }\end{array}$ & $\begin{array}{l}\text { - Ter atitude e } \\
\text { iniciativa; } \\
\text { - } \quad \text { Dar sugestões } \\
\text { e criar soluções para } \\
\text { problemas; } \\
\text { - } \quad \text { Ter } \\
\text { capacidade auto }\end{array}$ & $\begin{array}{l}\text { - Se atualizar } \\
\text { para não se tornar } \\
\text { obsoleto; } \\
\text { - } \quad \text { Estar sempre } \\
\text { antenado, atualizado, ter } \\
\text { afinidade com a } \\
\text { informática; }\end{array}$ & $\begin{array}{l}\text { - As lacunas são } \\
\text { preenchidas por } \\
\text { especializações e } \\
\text { experiência profissional } \\
\text { paralela ao curso. }\end{array}$ \\
\hline
\end{tabular}




\begin{tabular}{|c|c|c|c|}
\hline & $\begin{array}{l}\text { organizacional para } \\
\text { entregar as coisas no } \\
\text { prazo; } \\
\text { - } \quad \text { Adaptabilidade } \\
\text { - aprender rápido; }\end{array}$ & $\begin{array}{l}\text { - Resolver } \\
\text { problemas complexos - } \\
\text { conseguir integrar tudo; }\end{array}$ & \\
\hline $\begin{array}{l}\text { SABRINA } \\
\text { (PUC- } \\
\text { Administração- } \\
\text { penúltimo } \\
\text { período) }\end{array}$ & $\begin{array}{l}\text { - Raciocínio } \\
\text { rápido para resolver os } \\
\text { problemas; } \\
\text { - } \quad \text { Saber lidar } \\
\text { com as pessoas; } \\
\text { - } \quad \text { Excel } \\
\text { avançado; } \\
\text { - Inglês; } \\
\text { - Inteligência } \\
\text { emocional; }\end{array}$ & $\begin{array}{l}\text { - } \\
\text { ideias; } \\
\text { - } \quad \text { Inteligência } \\
\text { emocional; }\end{array}$ & $\begin{array}{l}\text { - Criatividade e } \\
\text { finanças pessoais. }\end{array}$ \\
\hline $\begin{array}{l}\text { LUíZA(PUC - } \\
\text { Administração- } \\
\text { penúltimo } \\
\text { período) }\end{array}$ & $\begin{array}{l}\text { - } \quad \text { Resolução de } \\
\text { conflitos; } \\
\text { - } \quad \text { Saber } \\
\text { trabalhar em grupo; }\end{array}$ & $\begin{array}{l}\text { - } \quad \text { Resiliência; } \\
\text { - } \quad \text { Saber e aceitar } \\
\text { lidar com mudanças; }\end{array}$ & $\begin{array}{l}\text { - O preencher de } \\
\text { qualquer lacuna } \\
\text { depende do esforço do } \\
\text { aluno. }\end{array}$ \\
\hline $\begin{array}{l}\text { VITÓRIA } \\
\text { (Estácio- } \\
\text { Administração } \\
\text { - 1ํ período) } \\
\text { fez por quase } 2 \\
\text { ano processos } \\
\text { gerenciais }\end{array}$ & $\begin{array}{l}\text { - Saber o que } \\
\text { faz e porque faz. } \\
\text { Saber executar; } \\
\text { - } \quad \text { Ter } \\
\text { experiência no cargo; } \\
\text { - Inteligência } \\
\text { emocional para tomar } \\
\text { decisão; }\end{array}$ & $\begin{array}{l}\text { - Especializações } \\
\text { fora da administração } \\
\text { que o agregue como } \\
\text { profissional - coisas } \\
\text { mais voltadas à } \\
\text { tecnologia; }\end{array}$ & $\begin{array}{l}\text { - Inteligência } \\
\text { emocional; } \\
\text { - } \quad \text { A universidade } \\
\text { não prepara o aluno } \\
\text { para a realidade, } \\
\text { somente dá teoria. }\end{array}$ \\
\hline
\end{tabular}

Fonte: A autora.

Percebe-se que, na opinião dos alunos, há predominância de competências comportamentais, como ter atitude e dar sugestões, raciocinar rápido, aprender rápido para se adaptar rápido, ter inteligência emocional, e interpessoais, como saber lidar com as pessoas, trabalhar em equipe e resolver conflitos. Saber 
resolver problemas, que podem ser rotineiros ou imprevisíveis também se destaca como importante, já que se repete mais de uma vez. Para o futuro, cada aluno citou uma opinião diferente, ao qual nenhuma delas pode ser descartada e a maioria entendeu que as lacunas deixadas pelas universidades em termos de competências comportamentais devem ser buscadas por fora, através do esforço de cada aluno. Cabe dizer que todas essas competências citadas também são contempladas como importantes segundo a literatura apresentada neste estudo.

Ao comparar as opiniões dos alunos com as dos gestores, percebe-se que os estudantes não enfatizam tanto o aprender a aprender, embora isto possa ser subentendido na participação de Lucas, quando fala sobre a importância de andar atualizado e necessidade de aprender rápido para se adaptar. É possível que isto aconteça devido o método de ensino tradicional que trata o aluno mais como um receptor de informações, que um aprendiz ativo. Por outro lado, os alunos conseguem enxergar a importância das habilidades interpessoais dada pelos gestores e pela literatura.

Quando foi perguntado se achavam que as universidades estão preparando bem os alunos para ingressarem no mercado de trabalho atual e futuro, a resposta unânime foi não, mas a maioria considera que depende muito mais do aluno se preparar para este cenário.

Os gestores mostraram que a principal lacuna do ensino é a falta do saber fazer e o os alunos disseram que o preenchimento dessas lacunas é de responsabilidade dos estudantes, então cabe aos estudantes a responsabilidade de buscar experiência profissional. Entretanto, no cenário brasileiro atual, segundo diversas reportagens do G1, a faixa etária mais afetada com o desemprego é a de jovens de 18 a 24 anos, que, apesar de graduados e com formação tecnóloga, estão desempregados ou com empregos fora da área de formação.

É possível que, diante deste cenário, as universidades promovam projetos pilotos que tragam as empresas para perto e realizem atividades que possam proporcionar uma certa experiência aos estudantes (metodologias ativas de aprendizagem possibilitam isso). Cabe às empresas também promover mais oportunidades para que estudantes sem experiência possam estagiar na área de interesse, e cabe aos estudantes buscar essas oportunidades e desenvolver outras competências que possam ser diferenciais para o seu currículo.

Segue a opinião sintetizada de cada professor que participou da entrevista: 
QUADRO 8 - As Competências Mais Importantes - Alunos

\begin{tabular}{|c|c|c|c|c|}
\hline \multicolumn{5}{|c|}{ Opinião dos Professores } \\
\hline & $\begin{array}{l}\text { COMPETÊNCIAS } \\
\text { IMPORTANTES }\end{array}$ & $\begin{array}{l}\text { PREPARAÇÃO } \\
\text { DOS JOVENS } \\
\text { PELAS } \\
\text { UNIVERSIDADES }\end{array}$ & $\begin{array}{l}\text { COMPETÊNCIA } \\
\text { S MENOS } \\
\text { TRABALHADAS }\end{array}$ & $\begin{array}{l}\text { METODOLOGIAS } \\
\text { ATIVAS AJUDAM? }\end{array}$ \\
\hline $\begin{array}{l}\text { SOLANGE } \\
\text { (7 anos } \\
\text { como } \\
\text { professora. } \\
\text { Leciona na } \\
\text { PUC-RIO e } \\
\text { ESPM) }\end{array}$ & $\begin{array}{ll}\bullet & \text { Resiliência } \\
\text { - } & \text { Liderança } \\
\text { - } & \text { Habilidade } \\
\text { s interpessoais } \\
\text { - } \quad \text { Visão } \\
\text { sistêmica }\end{array}$ & $\begin{array}{l}\text { - Não estão } \\
\text { preparados. }\end{array}$ & $\begin{array}{l}\text { - Habilida- } \\
\text { des interpessoais } \\
\text { como } \\
\text { comunicação e } \\
\text { negociação. } \\
\text { - Inteligên- } \\
\text { cia emocional } \\
\text { - Visão } \\
\text { sistêmica }\end{array}$ & $\begin{array}{l}\text { - Sim, o } \\
\text { estudo de caso } \\
\text { trabalha a visão } \\
\text { sistêmica e trabalho } \\
\text { por projeto, além de } \\
\text { outras, trabalham } \\
\text { relações } \\
\text { interpessoais }\end{array}$ \\
\hline $\begin{array}{l}\text { PEDRO } \\
\text { ANTÔNIO } \\
\text { (25 anos } \\
\text { como } \\
\text { professor. } \\
\text { Leciona na } \\
\text { PUC-RIO na } \\
\text { graduação e } \\
\text { MBA e na } \\
\text { FGV no } \\
\text { mestrado) }\end{array}$ & \begin{tabular}{lc} 
- & Trabalho \\
em equipe; \\
- & Saber ouvir \\
- & Negociaçã \\
0 & \\
- & Idioma \\
estrangeiro \\
- & Informática \\
- & Conhecer \\
os conteúdos de \\
\multicolumn{2}{l}{ cada área } \\
organizacional
\end{tabular} & $\begin{array}{l}\text { - Alguns sim. } \\
\text { Depende do esforço } \\
\text { do aluno em se } \\
\text { destacar. }\end{array}$ & - & - \\
\hline $\begin{array}{l}\text { AUGUSTO } \\
\text { (20 anos } \\
\text { como } \\
\text { professor. } \\
\text { Leciona na } \\
\text { PUC-RIO e }\end{array}$ & $\begin{array}{l}\text { - Inteligência } \\
\text { emocional, } \\
\text { resiliência são as } \\
\text { mais importantes; } \\
\text { - } \quad \text { Aprendizag } \\
\text { em ativa }\end{array}$ & $\begin{array}{l}\text { - Nas duas } \\
\text { instituições aos } \\
\text { quais eu trabalho } \\
\text { acho que sim. }\end{array}$ & - & $\begin{array}{l}\text { - Acredito que } \\
\text { as metodologias } \\
\text { ativas trabalham a } \\
\text { motivação na } \\
\text { aprendizagem dos } \\
\text { alunos que gostam }\end{array}$ \\
\hline
\end{tabular}




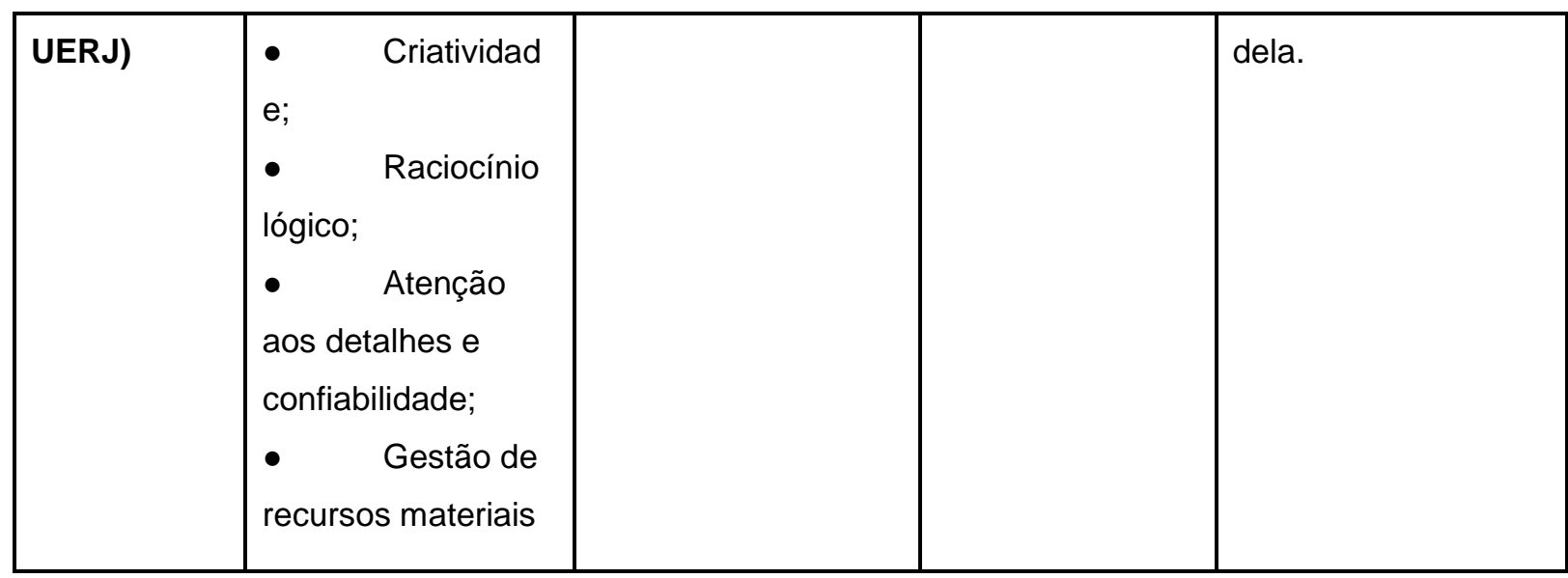

Fonte: A autora.

De acordo com a opinião dos professores, habilidades interpessoais como comunicação efetiva, trabalho em equipe e negociação são competências muito importantes e são valorizadas pela literatura, como apontam Fleury Fleury(2013) e Junior e Saltorato (2018).

Entretanto, percebe-se que a literatura traz como uma competência muito relevante a criatividade e esta não foi tão contemplada pelo grupo de professores entrevistados, e, embora tenha sido citada por alguns gestores e alunos como relevantes para o futuro, não teve a mesma consideração como competência essencial para o presente.

A maioria dos gestores cita a inovação como uma importante competência para o futuro, mas esta nem é lembrada pelos professores ou alunos.

\subsection{Análise dos Resultados}

Para melhor análise dos resultados as competências mais citadas durante as entrevistas serão segmentadas a seguir:

Mentalidade voltada para a aprendizagem, aprender a aprender, ser autodidata

Esta competência é a mais visada segundo os gestores Luís Carlos e Beatriz e é essencial segundo o estudante Lucas, quando ele fala sobre a 
necessidade de se andar atualizado para não ficar obsoleto em meio a um ambiente de constantes mudanças.

Tanto o Fórum Econômico Mundial, a síntese da literatura feita pro Junior e Saltorato (2018) acerca da 4⿳亠丷 Revolução e os autores Fleury e Fleury (2013) assumem esta competência como essencial para a atualidade e futuro. Entretanto, pouco é trabalhada pela escola tradicional que molda os alunos como aprendizes passivos.

A opinião de Luís Carlos acerca da preparação dada pelas universidades aos alunos é "As universidades hoje em dia só dão o ensino científico e o mercado de trabalho exige o saber fazer", e a de Beatriz "a forma de ensino precisa ser redesenhada para acompanhar a mudança mundial (...). É preciso conciliar teoria com a prática, conhecimento com pôr a mão na massa. É necessário repensar desde a base para preparar para este cenário. O desafio é conseguir a velocidade de aprendizagem sem perder a profundidade".

O objetivo da nova escola citada por Chaves (GUIMARÃES, 2012) é ensinar o aluno a fazer uma busca ativa pelo conhecimento, e colocar o professor como um facilitador e não como um transmissor de informações. O professor Augusto acredita que as metodologias ativas trabalham a motivação na aprendizagem dos alunos que gostam do método.

Embora o objetivo deste estudo não seja citar ou explicar os tipos de metodologia ativas, existem métodos que conciliam a prática com a teoria, como as visitas técnicas citadas, respectivamente, pelo gestor Luís Carlos e pela professora Solange:

"A dica que eu dou é fazer cursos à distância que permitem visitas técnicas. Esse método é usado pela Havard Business School. Esses cursos te obrigam a ter disciplina, foco, se aprofundar e a pôr a mão na massa, através das visitas agendadas na empresa. No final você precisa fazer algo como se fosse um TCC que compara toda a teoria aprendida com o que você viu em prática dentro da empresa". Uma observação importante é que Luís Carlos destacou que ser autodidata foi o grande diferencial da carreira dele.

"Eu trabalho com tantas metodologias ativas, com dramatização, games, projeto, TBL. Eu gostaria de trabalhar com uma metodologia que eu só testei com uma turma há muitos anos, que é não só fazer uma visita técnica, identificar um problema e propor uma solução para a empresa, mas dar as minhas aulas dentro 
de uma empresa, vivenciando um projeto de mudança. A gente ficou um bimestre e deu certo. Nem todas as empresas são abertas a isso, mas a empresária que solicitou a consultoria de gestão de mudança fazia parte da minha rede de relacionamento e eu propus fazer de forma gratuita e de forma acadêmica. Mas, em vários momentos a turma, que era pequena, queria desistir do projeto por achar que não dariam conta, por isso deve-se trabalhar a resiliência".

Esse tipo de método pode preencher a lacuna da falta de experiência e o não saber fazer tão citado por todos os gestores entrevistados.

\section{Inteligência emocional e resiliência}

Esta competência foi lembrada por praticamente todos os gestores, alunos e professores e é muito visada pela literatura como um fator importante para o

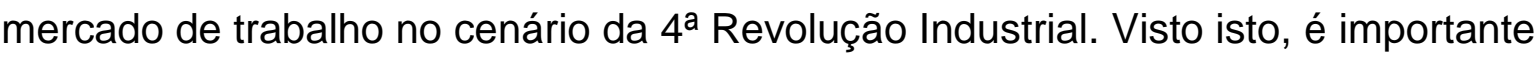
que esta competência seja trabalhada nas universidades, algo que não é possível enquanto o objetivo das escolas não for o desenvolvimento humano, e a escola for fechada em si, como citado por Guimarães (2012). É possível aplicar atividades dentro da sala de aula ou projetos que coloquem alunos para vivenciarem situações em que tenham de aprender a gerir a emoção através das metodologias ativas. E porque não fazer a gestão da emoção como uma disciplina obrigatória?

\section{Habilidades interpessoais - comunicação, liderança, trabalho em equipe, resolução de conflitos e negociação}

O saber comunicar de forma eficaz é uma competência enfatizada na literatura, entretanto não entrou no TOP 10 das competências do relatório 0 Futuro dos Trabalhos. De fato, a tecnologia que compõe a fábrica inteligente, a saber, a integração entre Sistema físico cibernético, Internet das coisas e internet em nuvem irá facilitar muito a comunicação, por permitir que as máquinas conversem entre si durante o processo, e o profissional acompanhe tudo em tempo real (BRITO, 2017).

Entretanto, a precarização das relações de trabalho (JUNIOR e SALTORATO, 2018) pode levar à contratação por curtos períodos de tempo para realizar serviços, que talvez necessitem de uma equipe, e, por isso, é importante 
ter esta competência bem desenvolvida. Além disso, essas habilidades são citadas por quase todos os entrevistados como competência considerada importante.

Para a professora Solange, as universidades deixam a desejar no desenvolvimento desta competência, e para suprir isto ela usa métodos ativos que, segundo ela, têm mostrado grandes resultados. Pela metodologia ativa favorecer não apenas a autoaprendizagem, mas também a aprendizagem coletiva, esta competência seria bem trabalhada na nova escola citada no trabalho de Guimarães (2012).

\section{Visão sistêmica}

Esta competência é valorizada por todos os grupos entrevistados, citadas pelo gestor Luís Carlos, pelo estudante Lucas e pela professora Solange. Embora não seja citada explicitamente na literatura, está implícita na resolução de problemas complexos, visto que é não é possível nem ao menos entender por completo o problema sem uma visão holística. Para Solange, a falta de visão sistêmica é uma lacuna deixada pelo ensino universitário, mas que pode ser sanado através do uso de metodologias ativas.

\section{Flexibilidade, adaptabilidade:}

Flexibilidade e adaptabilidade são consideradas pelos estudantes Lucas e Luíza, pela gestora Beatriz e pela literatura como competências muito importantes. Esta competência pouco pode ser trabalhada na escola tradicional, mas nas metodologias ativas sim, pois dão abertura para tal, não ficando fechada para si ou concentrada em um currículo fixo e pré-determinado.

\section{Criatividade:}

Embora tenha sido exacerbadamente citada pela literatura como uma competência fundamental para este cenário de constantes mudanças, percebeu que esta foi uma das competências menos valorizadas pelos entrevistados, principalmente pelo grupo dos professores. Talvez esse seja uma lacuna deixada 
pelo modo de pensar cartesiano das escolas, que segundo Ken Robinson (2010), inibem a criatividade. 


\subsection{CONCLUSÃO}

O presente estudo busca responder à seguinte questão: Diante do cenário de mudanças intensas da contemporaneidade, os cursos de Administração, oferecidos pelas universidades PUC- Rio, Unicarioca e Estácio de Sá do Rio de Janeiro, na percepção de estudantes, professores e profissionais de mercado, têm formado profissionais com as competências comportamentais e interpessoais adequadas para o mercado de trabalho?

Todos os pesquisados entenderam que apenas a graduação não é suficiente para se formar um administrador. Todos os grupos levantaram a importância do aspecto comportamental, emocional e interpessoal como competências relevantes para o mercado de trabalho atual e futuro, e compreendem a necessidade de buscar por fora do curso de graduação o desenvolvimento destas competências.

Observa-se que tanto os gestores quanto os alunos entrevistados estão percebendo as mudanças que a $4^{\text {a }}$ Revolução Industrial têm causado no mercado de trabalho e consideram como relevantes competências semelhantes às da literatura como essenciais para encarar este cenário desafiador, como a mentalidade voltada para aprendizagem, inteligência emocional, e habilidades interpessoais, tais como comunicação, trabalho em equipe, negociação. Entretanto, os entrevistados não deram tanto destaque à criatividade e inovação, como fez a literatura.

A escola tradicional não oferece possibilidades de desenvolvimento dessas competências, mas é possível ver as universidades caminhando para promover mudanças que vão além do método tradicional de ensino, visto que todos os professores citados trabalham com metodologias ativas.

No entanto, ainda há muitas competências a serem desenvolvidas pelos alunos a fim de suprirem a demanda do mercado de trabalho e garantir a empregabilidade dentro de um cenário inconstante.

Avalia-se, portanto, que as universidades não têm formado administradores com as competências comportamentais e interpessoais necessárias para enfrentar o mercado de trabalho no contexto desta nova revolução industrial, mas que, como mostrado na maioria das opiniões dos 
entrevistados, não foge da responsabilidade do aluno procurar desenvolver estas competências.

Para a continuidade deste estudo exploratório, é sugerido estudar e enfatizar competências de outras categorias, como a técnica, e que se use outros métodos de pesquisa, com a seleção de sujeitos de diferentes universidades e de ex-alunos. 


\subsection{REFERÊNCIAS BIBLIOGRÁGICAS}

As previsões do Fórum Econômico Mundial sobre o futuro do trabalho. Four Sales. Disponível em:<http://www.foursales.com.br/carreira/as-previsoes-doforum-economico-mundial-sobre-o-futuro-do-trabalho/>. Acesso em: 22 abr. 2019

BERGMANN, Jonathan e SAMS Aaron. Sala de aula invertida: uma metodologia ativa de aprendizagem. $1^{\text {a }}$ edição, Rio de Janeiro. Editora LTC, 2017.

BORBA, Jaqueline. A definição dos conhecimentos, habilidades e atitudes na formação de administradores na percepção de gestores, acadêmicos e legal. Disponível em: <http://www.convibra.com.br/upload/paper/adm/adm_2917.pdf>. Acesso em: 30 nov. 2018

BRASIL. Resolução ํㅡ 4, de 13 de julho de 2005. Diretrizes curriculares para os cursos de graduação. Disponível em: <http://www.cfa.org.br>. Acesso em: 30 mai. 2019

BRITO, Alexandra Antônia Freitas de Brito. A Quarta Revolução Industrial e as Perspectivas para o Brasil. Disponível em: $<$ https://www.nucleodoconhecimento.com.br/wp-content/uploads/artigocientifico/pdf/quarta-revolucao-industrial.pdf>. Acesso em 26 nov. 2018.

Como os jovens vão enfrentar a Quarta Revolução Industrial. EXAME. Disponível em:<https://exame.abril.com.br/carreira/como-os-jovens-vao-enfrentara-quarta-revolucao-industrial/>. Acesso em: 10 mai. 2019

COSTA, Cesar. INDÚSTRIA 4.0: O FUTURO DA INDÚSTRIA NACIONAL POSGERE (ISSN 2526-4982), v. 1, n. 4, set.2017, p. 5-14 Número Especial

Desemprego entre os jovens é superior ao dobro da taxa geral. G1 Globo. Disponível em: <https://g1.globo.com/economia/noticia/2018/08/17/desemprego- 
entre-os-jovens-e-superior-ao-dobro-da-taxa-geral-aponta-ibge.ghtml>. Acesso em 29 jun 2019.

FLEURY, Afonso; FLEURY, Maria. Estratégias Empresariais e Formação de Competências: Um quebra-cabeça Caleidoscópico da Indústria Brasileira. $3^{a}$ Edição. São Paulo. Editora Atlas SA, 2013

FLEURY, Maria Tereza Leme; OLIVEIRA JUNIOR, Moacir de Miranda. Gestão estratégica do conhecimento - Integrando aprendizagem, conhecimento e competências. São Paulo: Atlas, 2001.

FNQ. O que é um ambiente V.U.C.A. e o que isso tem a ver com gestão. Disponível em: <http://www.fnq.org.br/informe-se/noticias/o-que-e-um-ambiente-vu-c-a-e-o-que-isso-tem-a-ver-com-gestao>. Acesso em: 27 nov. 2018

Futuro do trabalho: Como será e o que você precisa saber? Four Sales. Disponível em: <http://www.foursales.com.br/carreira/futuro-do-trabalho-comosera/>. Acesso em: 04 abr 2019

GUIMARÃES, Maria Isabel Peixoto.Reaprendendo a aprender: o papel das competências metacognitivas. Dissertação (Mestrado em Engenharia de Produção) COPPE UFRJ, Rio de Janeiro.2012

Indústria 4.0: afinal, você sabe realmente o significado? TOTVS. Disponível em: <https://www.totvs.com/blog/industria-4-0-saiba-o-real-significado/>. Acesso em: 12 mai. 2019

JUNIOR, Geral Tessarani; SALTORATO, Patrícia. Impactos da indústria 4.0 na organização do trabalho: uma revisão sistemática da literatura. Disponível em: <https://producaoonline.org.br/rpo/article/view/2967/1678> Acesso em: 23 de maio. 2019 
KUPFER, David. Industria 4.0 Brasil - Valor econômico. Disponível em: <http://www.ie.ufrj.br/intranet/ie/userintranet/ienamidia/arquivo/080820165505_080 816_Indastria_4.0_Brasil.pdf>. Acesso em: 11 jan. 2019

Ministério da Indústria, Comércio e Serviços. Agenda Brasileira Para a Indústria 4.0. Disponível em: <http://www.industria40.gov.br/>. Acesso em: 27 nov. 2018.

OLIVEIRA, Maxwell. METODOLOGIA CIENTíFICA: um manual para a realização de pesquisas em administração. Disponível em: $<$ https://adm.catalao.ufg.br/up/567/o/Manual_de_metodologia_cientifica__Prof_Maxwell.pdf>. Acesso em 03 jun. 2019

Perfil, Formação, Atuação e Oportunidades de Trabalho. ANGRAD. Disponível em: $\quad$ <https://cfa.org.br/wp-content/uploads/2018/02/08Pesquisa-perfil2016_v3_web.pdf>. Acesso em: 12 mai. 2019

ROBINSON, Ken. Elemento Chave: Descubra onde a paixão se encontra com o seu talento e maximize seu potencial. $1^{1 \underline{a}}$ edição, Rio de Janeiro. Editora Ediouro, 2010

SCHWAB, K. A 4⿳亠丷厂 Revolução Industrial. 1aㅡ edição, Fórum Econômico Mundial. Crown Business: New York. ISBN: 9781524758869, 2016.

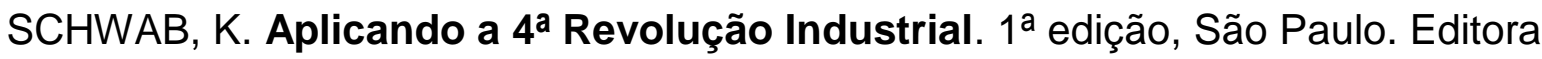
Edipro, 2018.

TAMINATO, Daniela Yoko. Você está vivendo no mundo VUCA e nem sabe o que é isso? Disponível em: <https://futuroexponencial.com/vivendo-mundovuca/>. Acesso em: 27 nov. 2018

TNH1. Como será o trabalho no mundo 'volátil, incerto, complexo e ambíguo'. Maceió, 20 de agosto de 2018. Disponível em: 
$<$ https://www.tnh1.com.br/noticia/nid/como-sera-o-trabalho-no-mundo-volatilincerto-complexo-e-ambiguo/>. Acessoem: 27 nov. 2018

World Economic Forum.The Future of Jobs Report 2018.Disponível em: http://www3.weforum.org/docs/WEF_Future_of_Jobs_2018.pdf Acesso em: 09 set 2018

World Economic Forum.The Future of Jobs Report 2016.Disponível em: http://www3.weforum.org/docs/WEF_Future_of_Jobs.pdf Acesso em: 09 set 2018

ZARIFIAN, Philippe. 0 modelo das competências trajetória histórica, desafios atuais e propostas. $2^{\mathrm{a}}$ edição. São Paulo. Editora Senac São Paulo, 2003 


\section{ANEXO A - ROTEIRO DE ENTREVISTA PARA PROFESSORES}

Nome, Tempo que leciona, disciplina que leciona, Instituições que leciona.

Quais competências você considera que o mercado de trabalho exige dos universitários de administração para ingressarem no mercado?

Você acha que os universitários estão saindo bem preparados das instituições de ensino para enfrentar a realidade do mercado atual e futuro, considerando a $4^{\text {a }}$ Revolução Industrial?

Quais competências você considera que as universidades menos trabalham?

Apresentar o quadro de competências levantado pelo relatório $O$ Futuro dos Trabalhos.

Você acredita que as metodologias ativas de aprendizagem possam trabalhar mais essas lacunas?

O que você mudaria no método de ensino, visto que existem vários modelos de metodologias ativas? 


\section{ANEXO B - ROTEIRO DE ENTREVISTA PARA ALUNOS}

Nome, idade, instituição de ensino, período da faculdade

Explicar o que é competência segundo a literatura

Quais competências você acha que o mercado de trabalho exige para contratar um administrador atualmente?

Estagia ou já estagiou?

Você sentiu alguma dificuldade devido a algum desalinhamento entre o que é aprendido na faculdade e o que é demandado no trabalho/estágio. Caso sim, de exemplos.

Quais são as competências que vc percebe que são menos trabalhadas nas universidades?

Falar um pouco da 4⿳亠丷厂 Revolução industrial e os impactos que pode causar na força de trabalho.

Quais competências você acha que o mercado de trabalho exige para contratar um administrador daqui a cerca de 3 anos?

Você conhece as competências que o Fórum Econômico Mundial falou que seria essencial em 2022 em seu relatório o futuro do trabalho?

Apresentar o quadro de competências levantado pelo relatório O Futuro dos Trabalhos.

Você acha que as universidades estão conseguindo preparar estudante para ingressar no mercado de trabalho atual? E no futuro? 


\section{ANEXO C - ROTEIRO DE ENTREVISTA PARA GESTORES}

Qual a área da empresa que você atua? Quanto tempo está nesta empresa? Quanto tempo tem de profissão?

Quais competências você considera importante ATUALMENTE para o profissional ingressar no mercado de trabalho?

Você acha que os universitários estão saindo bem preparados das universidades?

Você tem exemplos de casos positivos e negativos relacionados a essa preparação?

Quais são as competências que você percebe que são menos trabalhadas nas universidades?

Quais competências você acha que o mercado de trabalho exigirá para contratar um administrador no futuro?

Apresentar o quadro de competências levantado pelo relatório $O$ Futuro dos Trabalhos (Pesquisa feita a partir de entrevistas com ceo's que representam mais de 13 milhões de profissionais de nove grandes setores, em 15 mercados emergentes e desenvolvidos)

Você acha que as universidades estão conseguindo preparar estudante para ingressar no mercado de trabalho no futuro? 